\title{
Treatment of COVID-19 pneumonia and acute respiratory distress with ramatroban, a thromboxane $A 2$ and prostaglandin D2 receptor antagonist: A 4-Patient Case Series Report
}

\section{Martin L. Ogletree ( $\sim$ martin.ogletree@vanderbilt.edu )}

Department of Pharmacology, Vanderbilt University School of Medicine, Nashville, TN

Kate Chander Chiang

Charak Foundation, Orange, CA

Rashmi Kulshreshta

Regulatory Wisdom, Delhi, India

\section{Aditya Agarwal}

EyeSight Eye Hospital and Retina Centre, Madhya Pradesh, India

\section{Ashutosh Agarwal}

EyeSight Eye Hospital and Retina Centre, Madhya Pradesh, India

Ajay Gupta ( $\nabla$ ajayg1@hs.uci.edu )

Division of Nephrology, Hypertension and Kidney Transplantation, University of California Irvine, Orange, CA

\section{Case Report}

Keywords: COVID-19, SARS-CoV-2, thromboxane A2, prostaglandin D2, lipid storm, ramatroban, DPr2, TPr, thromboinflammation, thrombosis, platelet activation, NETs, immunomodulator, antithrombotic

Posted Date: January 4th, 2022

DOI: https://doi.org/10.21203/rs.3.rs-474882/v7

License: (c) (i) This work is licensed under a Creative Commons Attribution 4.0 International License. Read Full License 
Treatment of COVID-19 pneumonia and acute respiratory distress with ramatroban, a thromboxane $A_{2}$ and prostaglandin $D_{2}$ receptor antagonist: A 4-Patient Case Series Report

Martin L. Ogletree, $\mathrm{PhD}^{1^{*}}$; Kate Chander Chiang ${ }^{2}$, Rashmi Kulshreshta, $\mathrm{PhD}^{3}$, Aditya Agarwal, MBBS, $\mathrm{MS}^{4}$, Ashutosh Agarwal, MBBS, MS ${ }^{4}$, Ajay Gupta, MBBS, $\mathrm{MD}^{5 *}$

1. Department of Pharmacology, Vanderbilt University School of Medicine, Nashville, TN

2. Charak Foundation, Orange, CA

3. Regulatory Wisdom, Delhi, India

4. EyeSight Eye Hospital and Retina Centre, Madhya Pradesh, India

5. Division of Nephrology, Hypertension and Kidney Transplantation, University of California Irvine, Orange, CA

\section{*Corresponding Authors:}

Ajay Gupta, MBBS, MD

Division of Nephrology, Hypertension and Kidney Transplantation, University of California Irvine,

Orange, CA, USA

Email: ajayg1@hs.uci.edu

Phone: +1(562) 412-6259

Martin L. Ogletree, $\mathrm{PhD}$

Department of Pharmacology, Vanderbilt University School of Medicine, Nashville, TN, USA

Email: martin.ogletree@vanderbilt.edu

Phone: +1(267) 981-1296

\section{Word Count}

Abstract: 294

Main Body: 2900

Conflicts of Interest: Martin Ogletree has filed a patent claiming thromboxane receptor antagonists for the treatment of COVID-19. Ajay Gupta and Kate Chander Chiang have filed a patent on the use of a dual receptor antagonist of the thromboxane $\mathrm{A}_{2}$ and $\mathrm{PGD}_{2}-\mathrm{DPr} 2$ receptors for COVID-19. Dr. Gupta is the son of the index case reported here. The other authors did not declare any conflict of interest. 


\title{
KEY POINTS
}

Question: COVID-19 pneumonia sustains extraordinary lung accumulation of lipid mediators, especially thromboxane $\mathrm{A}_{2}$. Thromboxane $\mathrm{A}_{2}$ metabolites are associated with respiratory failure and mortality in COVID-19. Does blocking the effects of thromboxane $A_{2}$ using ramatroban, an orally bioavailable thromboxane receptor antagonist improve outcomes?

Findings: In this retrospective case series of 4 consecutive COVID-19 outpatients, respiratory distress and severe hypoxemia improved within 12-36 hours after starting ramatroban and normalized within 3-5 days with no need for hospitalization.

Meaning: In symptomatic COVID-19, ramatroban blocks thromboxane-receptor dependent pulmonary venoconstriction, bronchoconstriction and microvascular thrombosis to improve ventilation-perfusion matching, relieve hypoxemia, and promote resolution of pulmonary edema.

\begin{abstract}
Importance Hypoxemia in COVID-19 pneumonia is dispositive for hospitalization and mechanical ventilation and contributes to mortality. Other than oxygen supplementation, there is no treatment that resolves hypoxemia in COVID-19 pneumonia.
\end{abstract}

Objective COVID-19 pneumonia sustains a massive increase in lipid mediators, especially thromboxane $\mathrm{A}_{2} \gg \mathrm{PGE}_{2}>\mathrm{PGD}_{2}$. Thromboxane $\mathrm{A}_{2}$ induces pulmonary venoconstriction, increases pulmonary capillary pressure and contributes to pulmonary edema. High thromboxane $\mathrm{A}_{2}$ metabolite levels are strongly associated with respiratory failure and mortality in hospitalized COVID-19 patients. Ramatroban (Baynas ${ }^{\circledR}$, Bayer Yakuhin Ltd., Japan) is an inexpensive, orally bioavailable, thromboxane $\mathrm{A}_{2}$ receptor antagonist. Ramatroban was administered to patients with COVID-19 pneumonia and hypoxemia to explore the effect of thromboxane $\mathrm{A}_{2}$ antagonism on clinical symptoms and outcomes.

Design, Setting, and Participants A retrospective case series comprising 4 consecutive outpatients, 22 to 87 years of age, with COVID-19 pneumonia and hypoxemia treated with ramatroban between April and July 2021 in India.

Main Outcomes and Measures The primary outcome measure was blood oxygen saturation using pulse oximetry (SpO2). Secondary outcome measures were respiratory distress and need for hospitalization.

Results Four COVID-19 outpatients had developed progressive respiratory distress and hypoxemia. Within 12-36 hours of the first dose of ramatroban, all four patients experienced increase in $\mathrm{SpO} 2$ and decrease in respiratory distress, which obviated hospitalization. Continued treatment for 5 days was associated with complete resolution of respiratory distress and hypoxemia.

Conclusions and Relevance There is an unmet medical need for drugs that target the hemodynamic, prothrombotic, and maladaptive immune responses that lead to pneumonia and respiratory failure following SARS-CoV-2 infection. As an anti-vasospastic, broncho-relaxant, anti-thrombotic and 
immunomodulatory agent, ramatroban addresses the fundamental host response mechanisms underlying respiratory and critical organ failure in COVID-19. Ramatroban merits study in randomized clinical trials that might offer hope for a cost-effective pandemic treatment.

Abbreviations: Tx, thromboxane; $11 \mathrm{dhTxB}_{2}, 11$-dehydro-thromboxane $\mathrm{B}_{2}$; $\mathrm{TPr}$, thromboxane prostanoid receptor; PG, prostaglandin; COX, cyclooxygenase; DPr2, D prostanoid receptor 2; URTI, upper respiratory tract infection; BALF, bronchoalveolar lavage fluid; SARS-CoV-2, severe acute respiratory syndrome coronavirus 2; COVID-19, coronavirus disease 2019; RSV, respiratory syncytial virus; IL, interleukin; MDSC, monocyte-macrophage derived suppressor cell; IFN, interferon; ARDS, acute respiratory distress syndrome; SpO2, blood oxygen saturation by pulse oximetry; TGF- $\beta$, transforming growth factor beta; NK cells, natural killer cells; NETs, neutrophil extracellular traps 


\section{BACKGROUND}

After symptomatic SARS-CoV-2 infection, $10-20 \%$ of patients require hospitalization for respiratory distress and hypoxemia. ${ }^{1}$ Currently, anti-SARS-CoV-2 monoclonal antibodies are approved for treatment of ambulatory patients with COVID- $19,{ }^{2}$ and antiviral treatments have recently been approved, but they are expensive and effective only early after symptom onset. There is an unmet medical need for inexpensive, safe, orally bioavailable drugs that can reduce hypoxemia, provide symptomatic relief, and minimize hospitalization in patients with COVID-19. Identifying the correct therapeutic target is critical to discovering such a drug.

Lungs in COVID-19 patients with acute respiratory distress syndrome (ARDS) produce proinflammatory lipid mediators with predominance of cyclooxygenase metabolites in bronchoalveolar lavage fluid $(\mathrm{BALF})$, notably thromboxane $\mathrm{B}_{2}\left(\mathrm{TxB}_{2}\right)>>$ prostaglandin $\mathrm{E}_{2}\left(\mathrm{PGE}_{2}\right)>$ prostaglandin $\mathrm{D}_{2}\left(\mathrm{PGD}_{2}\right){ }^{3}$ The massive increase in $\mathrm{TxA}_{2}$ metabolites in $\mathrm{BALF}^{3}$ and systemically in hospitalized COVID-19 patients, ${ }^{4,5}$ suggests a critical role for $\mathrm{TxA}_{2} / \mathrm{TxA}_{2}$ prostanoid receptors (TPr) in COVID-19 respiratory distress. We hypothesized that $\mathrm{TxA}_{2} / \mathrm{TPr}$ induced contraction of pulmonary veins elevates pulmonary capillary pressure and contributes to pulmonary edema and hypoxemia in COVID-19 pneumonia (Fig. 1). TPr signaling leads to selective constriction of intrapulmonary veins and small airways with 10-fold higher potency and greater reduction in luminal area than intrapulmonary arteries. ${ }^{6}$ High local concentrations of $\mathrm{TxA}_{2}$ can effectively divert pulmonary blood flow, increase microvascular pressure and permeability, and force fluid and plasma proteins into alveoli. ${ }^{6}$ A selective TPr antagonist was previously reported to decrease pulmonary capillary pressure by selectively reducing post-capillary resistance in patients with acute lung injury. ${ }^{7} \mathrm{TxA}_{2}$ and isoprostanes stimulate TPr-mediated activation of the TGF $\beta$ pathway, ${ }^{8}$ and early, untimely TGF $\beta$ responses in SARS-CoV-2 infection limit antiviral function of natural killer (NK) cells and promote progression to severe COVID-19 disease. ${ }^{9}$

Theken and FitzGerald proposed early administration of a $\mathrm{TxA}_{2}$ antagonist as an antithrombotic agent, and a D-prostanoid receptor 2 (DPr2, formerly referred to as CRTH2) antagonist to boost interferon lambda (IFN- $\lambda$ ) in the upper respiratory tract, thereby limiting SARS-CoV-2 replication and transmission. ${ }^{10,11}$ Ramatroban, the only dual $\mathrm{TxA}_{2} / \mathrm{TPr}$ and $\mathrm{PGD}_{2} / \mathrm{DPr} 2$ receptor antagonist available for clinical study, has been proposed as an antithrombotic and immunomodulator agent in COVID-19. ${ }^{12,13}$ In their report showing very high levels of $\mathrm{TxB}_{2}>\mathrm{PGD}_{2}$ in $\mathrm{BALF}$, Archambault and colleagues also suggested ramatroban to block the deleterious effects of $\mathrm{TxA}_{2}$ and $\mathrm{PGD}_{2}$ in $\mathrm{COVID}-19 .{ }^{3}$ Ramatroban has an established safety profile, having been prescribed for over 20 years in Japan for treatment of allergic rhinitis. ${ }^{14,15}$ We report here a small case series of four consecutive COVID-19 patients with worsening respiratory distress and hypoxemia who were treated with ramatroban. Surprisingly, this led to rapid improvement in both respiratory distress and hypoxemia, thereby avoiding hospitalization and promoting recovery from acute disease.

\section{The $1^{\text {st }}$ case of severe COVID-19 pneumonia treated with ramatroban}

S.D., an 87-year-old Indian lady, experienced sudden onset of fever, cough, diarrhea, anorexia, profound weakness, and slight shortness of breath, 10 days after a 2-hour flight from New Delhi to Indore, Madhya 
Pradesh, India. Patient had received the first dose of COVAXIN, a whole virion inactivated vaccine against SARS-CoV-2, 30 days prior to beginning of symptoms. On examination the patient was fully alert, oriented, and able to make intelligent conversation but lay listlessly in bed unable to ambulate. Patient weighed $42 \mathrm{~kg}$ and exhibited severe pre-existing muscle wasting and marked kyphosis. Vital signs revealed temperature, $102^{\circ}$ Fahrenheit; heart rate, 100 per minute; blood pressure, 90/60 mm of Hg; and respiratory rate, 22 per minute. Mucosa were moist, and mild pallor was present. There was no jugular venous distention or pedal edema. Chest examination revealed bilateral coarse rales especially prominent at both lung bases but no wheezes. Abdomen, cardiovascular, and neurological examinations were unremarkable. Patient was not taking any medications.

Past medical history included hypertension for over 40 years; thyrotoxicosis for over 30 years treated with radioiodine therapy in 1999; severe osteoporosis with kyphosis; bladder suspension surgery in 1999; coronary artery disease leading to acute myocardial infarction and cardiac arrest in 2015 which required coronary angioplasty and stent placement; chronic kidney disease with estimated glomerular filtration rate of about $20 \mathrm{~mL} / \mathrm{min}$ (Table 2).

Investigations: Nasopharyngeal and oropharyngeal swabs were positive for SARS-CoV-2 infection by RNA PCR with cycle threshold ( $\mathrm{Ct}$ range $<20$ cycles). Pulse oximetry revealed oxygen saturation of about 85-88\%. Patient was admitted on April 9, 2021 to Medanta Hospital, Indore. CT scan revealed moderate multifocal, patchy ground glass opacities, and consolidation. There was septal thickening in the central and peripheral subpleural aspect of both lung parenchyma. Serial laboratory examinations during the course of the illness are listed in Table 1.

Hospital course: During the hospital stay, the patient was treated with high-flow nasal oxygen, prophylactic low-molecular weight heparin, intravenous remdesivir, antibiotics, and methylprednisolone. Patient continued to have fever, cough, shortness of breath, diarrhea, and profound weakness during the hospital stay. $\mathrm{SpO} 2$ on room air ranged between $82-86 \%$ (Table 2). After a hospital stay of 5 days, the patient was discharged upon her request on April 14, 2021. Discharge medications included oral oseltamivir, doxycycline, vitamin $\mathrm{C}$, aspirin $75 \mathrm{mg}$ once a day, $5 \mathrm{mg}$ prednisolone, vitamin $\mathrm{D}_{3}$, and nebulization with budesonide and salbutamol twice daily. Continued supportive management with betadine gargles, steam inhalation, and breathing exercises was advised.

Post-discharge course: On April 15, the day after discharge from the hospital, the patient had fever with a temperature of $101^{\circ}$ Fahrenheit. Pulse oximetry revealed an oxygen saturation (SpO2) of 82-84\% on room air, and patient was continued on oxygen. Patient was profoundly weak and unable to get out of bed without assistance. At this time all drugs including low-dose aspirin were discontinued, and the patient was started on ramatroban (Baynas ${ }^{\circledR}, 75 \mathrm{mg}$ tablet) in a dose of one-half tablet (37.5 mg) orally twice daily. The patient was continued on oxygen using a nasal cannula and $\mathrm{SpO} 2$ was not checked on room air. After about 36 hours, having received three one-half doses of ramatroban, there was noticeable improvement in her general condition, and $\mathrm{SpO} 2$ increased to $90 \%$ on room air. The dose of ramatroban was increased to $37.5 \mathrm{mg}$ in the morning and $75 \mathrm{mg}$ at bedtime. Patient had complete resolution of cough and diarrhea over the next 3 days and started ambulating independently without assistance. Ramatroban was discontinued after 2 weeks due to non-availability, and the patient was switched to $75 \mathrm{mg}$ aspirin daily. Patient had recovered almost completely by April 22, 2021, and gradually recovered fully over the 
next 3-4 weeks to baseline status. On October 10, 2021, 6 months after the acute COVID-19, a highresolution, non-contrast CT scan demonstrated non-homogenous ground glass pattern with normal lung volumes and absence of lung fibrosis. Patient continues to be asymptomatic.

Table 1. Serial laboratory values

\begin{tabular}{|l|c|c|c|c|}
\hline Analytes & $\begin{array}{c}\text { Before } \\
\text { admission }\end{array}$ & $\begin{array}{c}\text { During } \\
\text { hospital stay }\end{array}$ & $\begin{array}{c}\text { After } \\
\text { discharge }\end{array}$ & $\begin{array}{c}\text { Reference } \\
\text { Value }\end{array}$ \\
& $\begin{array}{c}\text { April 8, } \\
\mathbf{2 0 2 1}\end{array}$ & $\begin{array}{c}\text { April 13, } \\
\mathbf{2 0 2 1}\end{array}$ & $\begin{array}{c}\text { April 16, } \\
\mathbf{2 0 2 1}\end{array}$ & \\
\hline Hemoglobin (g/dl) & 11.7 & 12.1 & 12.0 & $13.0-17.0$ \\
\hline Platelet count (per mm m $\left.^{3}\right)$ & 214,000 & 285,000 & 402,000 & $150,000-$ \\
& & & & 410,000 \\
\hline WBC count (per mm ${ }^{3}$ ) & 5040 & 12100 & 9010 & $4000-10000$ \\
\hline Neutrophils (\%) & 77 & 80 & 86 & $38-70$ \\
\hline Lymphocytes (\%) & 18 & 11 & 07 & $21-49$ \\
\hline $\begin{array}{l}\text { NLR (Neutrophil-Lymphocyte } \\
\text { Ratio) }\end{array}$ & 4.3 & 7.3 & 12.3 & $1.1-3.5$ \\
\hline Serum CRP (mg/L) & 7.86 & 35.9 & 15.3 & $0-5.0$ \\
\hline D-dimer (ng FEU/mL) & 600 & 650 & 659 & $<500$ \\
\hline
\end{tabular}

\section{Case 2}

A.K., a 33-year-old business manager in New Delhi developed sore throat, cough, loss of smell, altered taste, loss of appetite, high grade fever (104-106 Fahrenheit), profound weakness and severe body aches around April 17, 2021. A.K. had not received the COVID-19 vaccine. Patient has past medical history of mild hypertension, psoriasis and psoriatic arthropathy treated with homeopathy, nasal polyposis and recurrent upper respiratory infections every winter for past several years. Nasopharyngeal and oropharyngeal swabs taken the next day were positive for SARS-CoV-2 infection by RNA PCR with cycle threshold (Ct range) of 21 cycles.

On April 18, 2021 the patient developed progressive shortness of breath and was started on oral favipiravir, hydroxychloroquine, doxycycline and multivitamins. SpO2 checked in the morning was about $90 \%$, declining to $82-85 \%$ by the evening. The shortness of breath worsened around midnight and patient could not catch his breath, was unable to speak, and was very anxious and restless. The $\mathrm{SpO} 2$ was $73 \%$ (Table 2). Patient could not be transferred to a COVID hospital due to nonavailability of hospital beds. Desperate attempts to secure an oxygen cylinder failed. Ramatroban was rushed to patient's home by Uber and first dose of $75 \mathrm{mg}$ was taken at 1:30 AM on the morning of April $19^{\text {th }}$. The "breathing improved in 25-30 minutes", the patient calmed down and fell asleep at 3 AM. Pulse oximetry remained disconnected while the patient was sleeping so as not to disturb him. Patient woke up at $11 \mathrm{AM}$ at which time $\mathrm{SpO} 2$ on room air was $88-90 \%$. On April $20^{\text {th }}$, oral temperature was $101^{\circ}$ Fahrenheit, and $\mathrm{SpO} 2$ was $90-92 \%$. Ramatroban was administered in a dose of $75 \mathrm{mg}$ twice daily for a total of 5 days. Patient continued to improve over the next 5 days (Table 2). On the $25^{\text {th }}$ of April, patient noticed that the sputum was streaked with blood and oral acetylcysteine was started. A chest CT on April $27^{\text {th }}$ revealed ground glass opacities involving bilateral lung fields with mild interstitial thickening giving the appearance of 
crazy-paving pattern. There were scattered areas of bronchopneumonic changes and consolidation involving both lungs. A few small fibrotic bands were noted in both lower lobes. The patient had made a near complete recovery by May $5^{\text {th }}$, and resumed work on May $10^{\text {th }}$. Patient continues to have altered taste and smell 7 months after the acute illness.

\section{Case 3}

S.B., a 22-year-old, healthy lady in New Delhi developed fever, cough, loss of smell and taste, and body aches due to COVID-19. S.B. had not received COVID vaccination. S.B. was treated with favipiravir, steroids and multivitamins. Patient experienced progressively worsening shortness of breath and $\mathrm{SpO}_{2}$ dropped to $85 \%$ on room air. Patient was prescribed Ramatroban $75 \mathrm{mg}$ twice daily. Within 6-8 hours after taking the first dose of ramatroban, respiratory distress improved and the $\mathrm{SpO} 2$ increased to $89 \%$. The next day $\mathrm{SpO} 2$ increased to $90-91 \%$. There was progressive improvement with complete resolution of respiratory symptoms over the next 5 days. On day 5, the $\mathrm{SpO}_{2}$ was $94 \%$ on room air (Table 2). Patient has made a complete recovery from COVID-19.

\section{Case 4}

B.C., a 70-year-old man living in a rural area of Bihar, India developed high grade fever and cough presumably secondary to SARS-CoV-2 infection. Patient has a history of diabetes mellitus controlled with diet. B.C. was not taking any medications and had only received one dose of COVAXIN vaccine for COVID-19. Patient developed shortness of breath with $\mathrm{SpO} 2$ measuring about $80 \%$ on room air. Two to three hours after taking $75 \mathrm{mg}$ ramatroban, respiratory distress and cough improved, and the $\mathrm{SpO} 2$ increased to $85 \%$. After a total of 10 tablets taken over 5 days, dyspnea had resolved, and $\mathrm{SpO} 2$ increased to $96 \%$ on room air (Table 2). Patient has made a complete recovery from COVID-19. 
Table 2. Clinical course of COVID-19 patients with acute respiratory distress treated with Ramatroban

\begin{tabular}{|c|c|c|c|c|}
\hline \multirow{2}{*}{$\begin{array}{c}\text { Patient Initials } \\
\text { Gender } \\
\text { Age (years) } \\
\text { Comorbidity }\end{array}$} & \multirow{2}{*}{$\begin{array}{c}\text { Ramatroban } \\
\text { (Baynas }{ }^{\circledR} \text { ) } \\
75 \text { mg tab }\end{array}$} & \multicolumn{3}{|c|}{ Clinical course; Blood oxygen saturation by pulse oximetry $\left(\mathrm{SpO}_{2}\right)$} \\
\hline & & $\begin{array}{c}\text { Time '0' } \\
\text { Ramatroban } \\
\text { started }\end{array}$ & $\begin{array}{l}\text { Time to partial relief of } \\
\text { dyspnea; and the first } \\
\text { SpO2 recorded on room } \\
\text { air after initiating } \\
\text { ramatroban treatment }\end{array}$ & $\begin{array}{c}\text { Day '5' after } \\
\text { taking } 10 \text { tablets } \\
\text { of ramatroban^ }\end{array}$ \\
\hline S.D.; female, 87 yrs. & $37.5 \mathrm{mg}$ & Dyspnea ++ & 24-36 hours; & No dyspnea \\
\hline $\begin{array}{c}\text { Hypertension; } \\
\text { Stage } 4 \text { CKD; CAD, MI } \\
\text { and cardiac arrest } 4 \text { years } \\
\text { ago }\end{array}$ & $\begin{array}{l}(1 / 2 \text { tab }) \\
\text { twice daily }\end{array}$ & $\mathrm{SpO} 2: 82 \%$ & $\begin{array}{c}\mathrm{SpO} 2>90 \%, 36 \text { hours after } \\
1^{\text {st }} \text { dose }^{*}\end{array}$ & $\mathrm{SpO} 2 \geq 95 \%$ \\
\hline A.K., male, 33 yrs & $75 \mathrm{mg}$ & Dyspnea +++ & 1-2 hours; & No dyspnea \\
\hline $\begin{array}{l}\text { Hypertension, psoriasis, } \\
\text { recurrent URTI }\end{array}$ & twice daily & $\mathrm{SpO} 2: 73 \%$ & $\begin{array}{c}\text { SpO2 90\%, } 9 \text { hours after } 1^{\text {st }} \\
\text { dose* }\end{array}$ & $\mathrm{SpO} 296 \%$ \\
\hline S.B., female, 22 yrs & $75 \mathrm{mg}$ & Dyspnea ++ & 4-6 hours; & No dyspnea \\
\hline & twice daily & $\mathrm{SpO} 2: 85 \%$ & $\begin{array}{c}\mathrm{SpO} 289 \%, 6-8 \text { hours after } \\
1^{\text {st }} \text { dose }\end{array}$ & $\mathrm{SpO} 294 \%$ \\
\hline B.C., male, 70 yrs & $75 \mathrm{mg}$ & Dyspnea ++ & 2-3 hours; & No dyspnea \\
\hline Diabetes mellitus & twice daily & $\mathrm{SpO} 2: 80 \%$ & $\begin{array}{c}\text { SpO2 } 85 \%, 2-3 \text { hours after } \\
1^{\text {st }} \text { dose }\end{array}$ & $\mathrm{SpO} 296 \%$ \\
\hline
\end{tabular}

*SpO2 on room air was not checked at earlier time points

$\wedge^{\wedge}$ For patients 2, 3, and 4, ramatroban could be administered only for a total of 5 days due to limited supplies.

\section{Discussion}

We present the first reported cases of COVID-19 treated with ramatroban (Baynas ${ }^{\circledR}$ ), a dual antagonist of the $\mathrm{TxA}_{2} / \mathrm{TPr}$ and $\mathrm{PGD}_{2} / \mathrm{DPr} 2$ receptors. All four COVID-19 patients were characterized by respiratory distress that was new in onset or had worsened (Table 2). Despite presenting with severe hypoxemia, gas exchange rapidly improved in all four patients. They were able to avoid hospitalization and recovered without any further need for supplemental oxygen or corticosteroids.

Relief of hypoxemia is a key success factor in COVID-19 treatment. The rapidity of improvement following oral ramatroban is consistent with acute relaxation of vascular and airway smooth muscles. We hypothesize blocking $\mathrm{TxA}_{2} / \mathrm{TPr}$ inhibits pulmonary venous constriction, lowers pulmonary capillary pressure, and relaxes bronchial smooth muscle. A TPr-dependent pressure gradient across the pulmonary microvasculature can force fluid from the vascular compartment into the alveoli, overwhelm lymphatics and flood the small airways, leading to pulmonary edema ${ }^{6}$ (Fig. 1). 


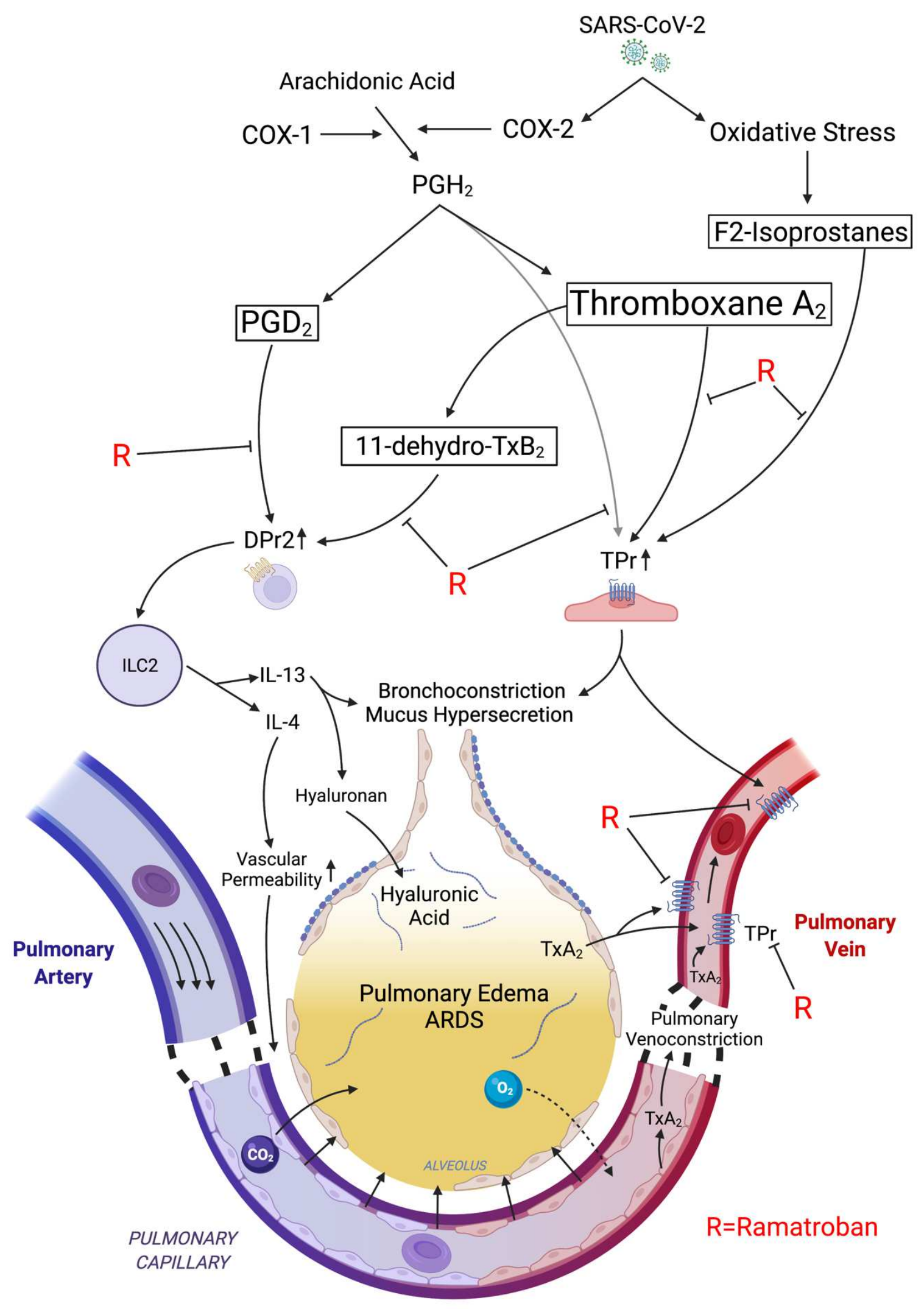


Figure 1. Proposed mechanisms of rapid relief in respiratory distress following ramatroban administration during acute SARS-CoV-2 infection. SARS-CoV-2 induced expression of COX-2 generates $\mathrm{PGH}_{2}$ which is converted into thromboxane $\mathrm{A}_{2}>\mathrm{PGD}_{2}$. Oxidative stress associated free radicals initiate non-enzymatic peroxidation of arachidonic acid leading to F2-isoprostane generation. $\mathrm{PGH}_{2}, \mathrm{TxA}_{2}$ and $\mathrm{F}$ 2-isoprostanes stimulate thromboxane prostanoid receptors (TPr). TPr stimulation induces pulmonary venoconstriction leading to an increase in transcapillary pressure in pulmonary microvasculature, and transudation of fluid into the alveoli, thereby causing impaired gas exchange and ARDS. TxA $A_{2} / \mathrm{TPr}$ axis also induces bronchoconstriction and mucus secretion. TxA $\mathrm{A}_{2}$ is rapidly converted to 11-dehydro- $\mathrm{TxB}_{2}$ in the lungs. $\mathrm{PGD}_{2}$ and 11-dehydro- $\mathrm{TxB}_{2}$ stimulate the $\mathrm{DPr} 2$ receptor on $\mathrm{Th} 2$ and ILC2 cells leading to release of type 2 cytokines, IL-4 and IL-13. IL-4 promotes vascular permeability thereby exacerbating fluid transudation while IL-13 induces hyaluronic acid accumulation and mucus hypersecretion. Ramatroban inhibits the DPr2 and TPr receptors thereby promoting pulmonary vasorelaxation, bronchorelaxation and improving capillary barrier function, while attenuating the maladaptive type 2 immune response and mucus secretion, thereby alleviating pulmonary edema and ARDS. Tx, thromboxane; PG, prostaglandin; TPr, thromboxane prostanoid receptor; DPr2; D-prostanoid receptor 2; Th2; T helper 2; ILC2; innate lymphoid class 2

$\mathrm{U}-46619$, a $\mathrm{PGH}_{2}$ analog TPr agonist, at $1 \mathrm{nM}$ reduced guinea-pig pulmonary venous and airways luminal areas by $50 \%$ with little or no change in arterial luminal area. ${ }^{6}$ Higher concentrations collapsed both pulmonary veins and airways, indicating that sub-nanomolar concentrations of the more potent $\mathrm{TxA}_{2}$ could produce meaningful increases in airway tone and pulmonary venous resistance. ${ }^{6}$ This is consistent with the measured effect of ifetroban, a selective TPr antagonist which reduced pulmonary venous resistance and capillary pressure in patients with acute lung injury. ${ }^{16}$ Moreover, TPr antagonism prevented hypoxemia in a lethal porcine septic shock model, ${ }^{17}$ attenuated airway mucus hyperproduction induced by cigarette smoke ${ }^{18}$ and reduced pulmonary edema in mouse models of acute lung injury. ${ }^{19}$ In the patient cases presented here, we hypothesize that ramatroban enhanced pulmonary blood flow, reduced pulmonary capillary pressures, improved ventilation-perfusion matching, promoted resolution of edema, reduced bronchoconstriction and airway mucus hyperproduction, improved lung compliance and gas exchange, and thereby mitigated SARS-CoV-2 respiratory distress and hypoxemia (Fig. 1 and Table 3).

Lung $\mathrm{TxA}_{2}$ generation is sufficiently elevated in symptomatic COVID-19 that TPr activation may affect other critical organ functions. For example, vascular effects might include vasospasm and thrombosis resulting in angina, arrhythmias, myocardial infarction and/or stroke. ${ }^{20}$ In the cerebral circulation, TPr activation can increase blood-brain barrier permeability, ${ }^{21}$ which may contribute to brain fog in COVID19. The potential of TPr blockade to affect the lungs and other critical organs during acute illness and during convalescence or long COVID merits focused research. 
Table 3. Proposed effect of antagonizing Thromboxane $A_{2} / T P r$ and Prostaglandin $D_{2} / D P r 2$ signaling by ramatroban in patients with COVID-19

\begin{tabular}{|c|c|c|}
\hline COVID-19 & Thromboxane $A_{2} / T P r$ & Prostaglandin $\mathrm{D}_{2} / \mathrm{DPr} 2$ \\
\hline $\begin{array}{l}\text { Endogenous } \\
\text { agonists for the } \\
\text { receptors }\end{array}$ & $\begin{array}{c}\text { Thromboxane } \mathrm{A}_{2} \\
\text { F2-Isoprostanes } \\
\text { Prostaglandin } \mathrm{H}_{2}\end{array}$ & $\begin{array}{c}\text { Prostaglandin } \mathrm{D}_{2} \\
\text { 11-dehydro-thomboxane } \mathrm{B}_{2}\end{array}$ \\
\hline $\begin{array}{l}\text { Acute effects } \\
\text { of antagonism } \\
\text { (minutes-hours) }\end{array}$ & $\begin{array}{c}\text { Hypoxemia } \downarrow, \text { V/Q mismatch } \downarrow \\
\text { Bronchoconstriction } \downarrow \\
\text { Pulmonary edema } \downarrow \\
\Uparrow \\
\text { Pulmonary microvascular permeability } \downarrow \\
\text { Pulmonary capillary pressure } \downarrow \\
\text { Pulmonary venous constriction } \downarrow \\
\text { NK cell SARS-CoV-2 killing } \uparrow \\
\Uparrow \\
\text { TGF } \beta \downarrow\end{array}$ & $\begin{array}{c}\text { Hyaluronan accumulation } \downarrow \\
\Uparrow \\
\text { IL- } 13 \downarrow \\
\text { Antiviral } \\
\Uparrow \\
\text { IFN- } \lambda \uparrow\end{array}$ \\
\hline $\begin{array}{l}\text { Subacute short-term } \\
\text { effect of antagonism } \\
\text { (days-weeks) }\end{array}$ & $\begin{array}{c}\text { Microvascular thrombosis } \downarrow \\
\text { Anti-inflammatory (thromboinflammation } \downarrow \text { ) }\end{array}$ & $\begin{array}{c}\text { Antiviral activity } \\
\Uparrow \\
\text { Th1 Response } \uparrow \\
\text { Th2 Response } \downarrow\end{array}$ \\
\hline $\begin{array}{l}\text { Long-term effect of } \\
\text { antagonism } \\
\text { (weeks-months) }\end{array}$ & $\begin{array}{c}\text { Brain fog } \downarrow \text {, Brain edema } \downarrow \\
\Uparrow \\
\text { Blood-brain barrier } \uparrow \\
\text { Lung fibrosis } \downarrow \\
\Uparrow \\
\text { TGF } \beta \downarrow\end{array}$ & $\begin{array}{c}\text { Depression } \downarrow \\
\text { Activity } \uparrow\end{array}$ \\
\hline
\end{tabular}

$\mathrm{PGD}_{2}$ / DPr2 signaling promotes allergic inflammation by stimulating Th2 and innate lymphocyte class 2 (ILC2) cells as in asthma (Fig. 1). ${ }^{22,23}$ The maladaptive immune response in COVID-19 is characterized by a shift from Th1 to Th2 with basophilia, eosinophilia, lymphopenia and an increase in plasma levels of type 2 cytokines produced by Th2 cells, including IL-4 and IL-13. ${ }^{24-26}$ IL-4 is known to impair the barrier function of endothelial cells, leading to microvascular leakage and edema formation (Fig. 1) ${ }^{27}$ IL-13 increases hyaluronan accumulation in mouse lungs ${ }^{28}$ and mucus overproduction in cultured human bronchial epithelial cells. ${ }^{29}$ This is correlated with ARDS, need for mechanical ventilation, acute kidney injury (AKI), and mortality in COVID-19. ${ }^{30}$ Whether ramatroban inhibits inflammation and hyaluronan accumulation in ARDS remains to be investigated.

The beneficial effects of ramatroban may be additionally attributed to enhanced antiviral activity due to $\mathrm{TxA}_{2} / \mathrm{TPr}$ and $\mathrm{PGD}_{2} / \mathrm{DPr} 2$ antagonism. First, TxA $2 / \mathrm{TPr}$ activation stimulates activation of the TGF- $\beta$ pathway, ${ }^{8}$ and early, untimely TGF- $\beta$ responses in SARS-CoV-2 infection limit antiviral function of 
natural killer (NK) cells. ${ }^{9}$ Second, TxA $\mathrm{A}_{2} / \mathrm{TPr}$ activation may directly modulate natural cytotoxic effector cell function. ${ }^{31}$ Third, $\mathrm{PGD}_{2} / \mathrm{DPr} 2$ signaling may suppress innate mucosal antiviral responses by inhibiting expression of interferon (IFN)- $\lambda$, the first line of defense against viruses at mucosal surfaces. Notably IFN- $\lambda$ is markedly suppressed in the upper respiratory tract in COVID-19. ${ }^{32}$ Increased expression of phospholipase $\mathrm{A}_{2}$ group IID and $\mathrm{PGD}_{2}$ in the elderly may further suppress IFN- $\lambda$ expression, ${ }^{33}$ thereby impairing antiviral responses and contributing to increased morbidity and mortality observed consistently in the elderly. ${ }^{11}$ Expression of nasal and pharyngeal $\mathrm{PGD}_{2}$ and DPr2 in SARS-CoV-2 infection remain to be investigated even though there is significant elevation of $\mathrm{PGD}_{2}$ in bronchoalveolar lavage fluid and human lung epithelial cells, ${ }^{3,34}$ and expression of $\mathrm{PGD}_{2}$ synthase and DPr2 in COVID-19 kidneys. ${ }^{35}$ Interestingly, 11-dehydro- $\mathrm{TxB}_{2}\left(11 \mathrm{dhTx} \mathrm{B}_{2}\right)$, a major stable metabolite of thromboxane $\mathrm{A}_{2}$, serves as a full agonist of DPr2 receptors. ${ }^{36}$ Urinary $11 \mathrm{dhTxB}_{2}$ levels are markedly increased in COVID-19 and correlate with length of hospitalization, mechanical ventilation and mortality. ${ }^{37}$ In rabbits infused with $\mathrm{TxB}_{2}$, $11 \mathrm{dhTxB}_{2}$ was a major metabolite, and enzymatic conversion of $\mathrm{TxB}_{2}$ to $11 \mathrm{dhTxB}_{2}$ was not detected in blood cells or plasma. ${ }^{38}$ The dehydrogenase catalyzing formation of $11 \mathrm{dhTxB}_{2}$ was tissue bound with the highest activity in lung. ${ }^{38}$ The above suggests that elevated lung $\mathrm{TxA}_{2}$ is converted to $11 \mathrm{dhTxB} \mathrm{B}_{2}$ wich may exert local or systemic effects via DPr2. In a neonatal mouse model of severe respiratory syncytial virus-induced bronchiolitis, treatment with a DPr2 antagonist decreased viral load and improved morbidity associated with upregulating interferon (IFN)- $\lambda$ expression. ${ }^{10,33}$ Whether ramatroban enhances NK cell and IFN- $\lambda$ responses and reduces SARS-CoV-2 viral load remains to be investigated.

Currently, there is no treatment for long COVID symptoms following recovery from acute illness. Long COVID is often characterized by neuropsychiatric manifestations including "brain fog," anxiety or depression, fatigue and problems with mobility, dyspnea, in part due to lung fibrosis and lung diffusion impairment, and microvascular thrombosis persisting for $>4$ months in about $25 \%$ of patients. ${ }^{39,40}$ Despite persistence of ground glass opacities 6 months later in patient 1, lung fibrosis was not detected. This is consistent with the antifibrotic effect of ramatroban in an animal model of silicosis that is associated with markedly increased pulmonary thromboxane $\mathrm{A}_{2}$ and $\mathrm{PGD}_{2} \cdot{ }^{41}$ Moreover, in well-established animal models of depression, elevation in $\mathrm{PGD}_{2}$ mediates depression-like behavior, while ramatroban restores object exploration and social interaction. ${ }^{42}$ The above suggests that ramatroban may help prevent and/or treat certain long COVID symptoms (Table 3).

This report has several limitations. Only 4 patients could be treated with ramatroban, and the duration of treatment was brief due to very limited availability of the drug in India. Only the first patient had laboratory studies performed. Patients 2, 3 and 4 were not examined by a physician and the clinical course was reported by patients or their relatives.

During the ongoing pandemic, there is an unmet need for a drug that can provide rapid relief of respiratory symptoms and hypoxemia, halt progression of disease, and minimize hospitalization, which is associated with poor outcomes for the patient and added burden on the healthcare system. Ramatroban (Baynas ${ }^{\circledR}$, Bayer Yakuhin, Ltd., Japan) has been safely used for the treatment of allergic rhinitis in Japan since 2000. ${ }^{15}$ The usual adult oral dose of $75 \mathrm{mg}$ twice daily achieves an average plasma concentration of about $0.1 \mathrm{mg} / \mathrm{L}$ or $240 \mathrm{nM}$ which is sufficient to inhibit pulmonary venous constriction, platelet activation, and release of type 2 cytokines (Table 3 ). 
The rapid and salutary responses to ramatroban reported here, its diverse actions targeting the major pathobiologic mechanisms underlying COVID-19 (Table 1 and Fig. 1), coupled with its oral bioavailability and an excellent safety profile make ramatroban an attractive therapeutic agent to test in randomized controlled clinical trials.

\section{References}

1. Trust for American's Health. CDC Data Show High Hospitalization Rates for Diagnosed COVID-19 Patients with Underlying Conditions in the United States. 2021. https://www.tfah.org/wp-content/uploads/2020/04/COVIDunderlyingconditions040320.pdf (accessed October 30 2021).

2. NIH. What's New in the Guidelines. 2021.

https://www.covid19treatmentguidelines.nih.gov/about-the-guidelines/whats-new/ (accessed October 30 2021).

3. Archambault AS, Zaid Y, Rakotoarivelo V, et al. High levels of eicosanoids and docosanoids in the lungs of intubated COVID-19 patients. The FASEB Journal 2021; 35(6).

4. Al-Hakeim HK, Al-Hamami SA, Almulla AF, Maes M. Increased Serum Thromboxane A2 and Prostacyclin but Lower Complement C3 and C4 Levels in COVID-19: Associations with Chest CT Scan Anomalies and Lowered Peripheral Oxygen Saturation. COVID 2021; 1(2): 489-502. 5. Hottz ED, Azevedo-Quintanilha IG, Palhinha L, et al. Platelet activation and plateletmonocyte aggregates formation trigger tissue factor expression in severe COVID-19 patients. Blood 2020.

6. Larsson AK, Hagfjärd A, Dahlén SE, Adner M. Prostaglandin $\mathrm{D}_{2}$ induces contractions through activation of TP receptors in peripheral lung tissue from the guinea pig. Eur $J$ Pharmacol 2011; 669(1-3): 136-42.

7. Walch L, De Montpreville V, Brink C, Norel X. Prostanoid EP1- and TP-receptors involved in the contraction of human pulmonary veins. British Journal of Pharmacology 2001; 134(8): 1671-8.

8. Craven PA, Studer RK, DeRubertis FR. Thromboxane/Prostaglandin EndoperoxideInduced Hypertrophy of Rat Vascular Smooth Muscle Cells Is Signaled by Protein Kinase CDependent Increases in Transforming Growth Factor- $\beta$. Hypertension 1996; 28(2): 169-76.

9. Witkowski M, Tizian C, Ferreira-Gomes $M$, et al. Untimely TGF $\beta$ responses in COVID-19 limit antiviral functions of NK cells. Nature 2021.

10. Theken KN, Fitzgerald GA. Bioactive lipids in antiviral immunity. Science 2021;

371(6526): 237-8.

11. Sposito B, Broggi A, Pandolfi L, et al. The interferon landscape along the respiratory tract impacts the severity of COVID-19. Cell 2021.

12. Gupta A, Kalantar-Zadeh K, Srinivasa RT. Ramatroban as a Novel Immunotherapy for COVID-19. Molecular and Genetic Medicine 2020; 14(3).

13. Gupta A, Chiang KC. Prostaglandin D2 as a mediator of lymphopenia and a therapeutic target in COVID-19 disease. Medical Hypotheses 2020; 143: 110122. 
14. Uller L, Mathiesen JM, Alenmyr L, et al. Antagonism of the prostaglandin D2 receptor CRTH2 attenuates asthma pathology in mouse eosinophilic airway inflammation. Respiratory Research 2007; 8(1).

15. Ishizuka T, Matsui T, Okamoto Y, Ohta A, Shichijo M. Ramatroban (BAY u 3405): a novel dual antagonist of TXA2 receptor and CRTh2, a newly identified prostaglandin D2 receptor. Cardiovasc Drug Rev 2004; 22(2): 71-90.

16. Schuster DP, Kozlowski J, Brimiouelle S. Effect of thromboxane receptor blockade on pulmonary capillary hypertension in acute lung injury. 2001 Meeting of the American Thoracic Society. San Francisco, CA; 2001.

17. Slotman GJ, Quinn JV, Burchard KW, Gann DS. Thromboxane interaction with cardiopulmonary dysfunction in graded bacterial sepsis. J Trauma 1984; 24(9): 803-10.

18. An J, Li JQ, Wang $T$, et al. Blocking of thromboxane $A(2)$ receptor attenuates airway mucus hyperproduction induced by cigarette smoke. Eur J Pharmacol 2013; 703(1-3): 11-7. 19. Kobayashi K, Horikami D, Omori K, et al. Thromboxane A2 exacerbates acute lung injury via promoting edema formation. Scientific Reports 2016; 6(1): 32109.

20. Bauer J, Ripperger A, Frantz S, Ergün S, Schwedhelm E, Benndorf RA. Pathophysiology of isoprostanes in the cardiovascular system: implications of isoprostane-mediated thromboxane A2receptor activation. British Journal of Pharmacology 2014; 171(13): 3115-31.

21. Zhao Z, Hu J, Gao X, et al. Hyperglycemia via activation of thromboxane A2 receptor impairs the integrity and function of blood-brain barrier in microvascular endothelial cells. Oncotarget 2017; 8(18): 30030-8.

22. Xue L, Gyles SL, Wettey FR, et al. Prostaglandin D2 Causes Preferential Induction of Proinflammatory Th2 Cytokine Production through an Action on Chemoattractant Receptor-Like Molecule Expressed on Th2 Cells. The Journal of Immunology 2005; 175(10): 6531-6.

23. Xue L, Salimi M, Panse I, et al. Prostaglandin D2 activates group 2 innate lymphoid cells through chemoattractant receptor-homologous molecule expressed on TH2 cells. Journal of Allergy and Clinical Immunology 2014; 133(4): 1184-94.e7.

24. Yang L, Liu S, Liu J, et al. COVID-19: immunopathogenesis and Immunotherapeutics. Signal Transduction and Targeted Therapy 2020; 5(1).

25. Lucas $\mathrm{C}$, Wong $\mathrm{P}$, Klein J, et al. Longitudinal analyses reveal immunological misfiring in severe COVID-19. Nature 2020; 584(7821): 463-9.

26. Perlman S. COVID-19 poses a riddle for the immune system. Nature 2020; 584(7821): 345-6.

27. Skaria T, Burgener J, Bachli E, Schoedon G. IL-4 Causes Hyperpermeability of Vascular Endothelial Cells through Wnt5A Signaling. PLOS ONE 2016; 11(5): e0156002.

28. Donlan AN, Sutherland TE, Marie C, et al. IL-13 is a driver of COVID-19 severity. JCI Insight 2021.

29. Tanabe T, Fujimoto K, Yasuo M, et al. Modulation of mucus production by interleukin-13 receptor alpha2 in the human airway epithelium. Clin Exp Allergy 2008; 38(1): 122-34.

30. Gómez-Escobar LG, Hoffman KL, Choi JJ, et al. Cytokine signatures of end organ injury in COVID-19. Scientific Reports 2021; 11(1): 12606.

31. Rola-Pleszczynski M, Gagnon L, Bolduc D, LeBreton G. Evidence for the involvement of the thromboxane synthase pathway in human natural cytotoxic cell activity. J Immunol 1985; 135(6): 4114-9. 
32. Broggi A, Ghosh S, Sposito B, et al. Type III interferons disrupt the lung epithelial barrier upon viral recognition. Science 2020; 369(6504): 706-12.

33. Werder RB, Lynch JP, Simpson JC, et al. PGD2/DP2 receptor activation promotes severe viral bronchiolitis by suppressing IFN-lambda production. Sci Transl Med 2018; 10(440).

34. Ricke-Hoch $M$, Stelling E, Lasswitz L, et al. Impaired immune response mediated by prostaglandin E2 promotes severe COVID-19 disease. PLOS ONE 2021; 16(8): e0255335.

35. Diao $B$, Wang $C$, Wang $R$, et al. Human kidney is a target for novel severe acute respiratory syndrome coronavirus 2 infection. Nature Communications 2021; 12(1): 2506.

36. Böhm E, Sturm GJ, Weiglhofer I, et al. 11-Dehydro-thromboxane B2, a Stable Thromboxane Metabolite, Is a Full Agonist of Chemoattractant Receptor-homologous Molecule Expressed on TH2 Cells (CRTH2) in Human Eosinophils and Basophils. Journal of Biological Chemistry 2004; 279(9): 7663-70.

37. Tantry US, Bliden KP, Cho A, et al. First Experience Addressing the Prognostic Utility of Novel Urinary Biomarkers in Patients With COVID-19. Open Forum Infectious Diseases 2021; 8(7).

38. Westlund $P$, Kumlin $M$, Nordenström A, Granström E. Circulating and urinary thromboxane B2 metabolites in the rabbit: 11-dehydro-thromboxane B2 as parameter of thromboxane production. Prostaglandins 1986; 31(3): 413-43.

39. Townsend L, Fogarty H, Dyer A, et al. Prolonged elevation of D-dimer levels in convalescent COVID-19 patients is independent of the acute phase response. $J$ Thromb Haemost 2021; 19(4): 1064-70.

40. Huang L, Yao Q, Gu X, et al. 1-year outcomes in hospital survivors with COVID-19: a longitudinal cohort study. The Lancet 2021; 398(10302): 747-58.

41. Pang J, Qi X, Luo Y, et al. Multi-omics study of silicosis reveals the potential therapeutic targets PGD(2) and TXA(2). Theranostics 2021; 11(5): 2381-94.

42. Onaka $\mathrm{Y}$, Shintani N, Nakazawa T, et al. CRTH2, a prostaglandin D2 receptor, mediates depression-related behavior in mice. Behavioural Brain Research 2015; 284: 131-7. 